as he saw it. Magnificent photographs illuminate the text which is rich in fascinating facts and well seasoned with little known Indian legends and personal anecdotes. Illus. $\$ 7.25$

THE WHITE COLT by David Rock. The author's wide-ranging knowledge of horses, and his understanding of the place of nature in the lives of people, makes this story of a small boy's struggle against the greatest odds, a moving experience. $\$ 4.65$

WONDERS OF THE BAT WORLD by Sigmund A. Lavine. Despite numerous superstitious fancies the bat is one of man's best friends. Its beneficial habits are stressed in this lively summary of what we have learned about this flying mammal, including the s.onar system. 64 pp., ages 8-12. $\$ 3.95$

THE WORLD OF THE AMERICAN ELK by Joe Van Wormer. In this delightful and informative book the author examines the elk in all aspects in all four seasons, illustrating his anecdotes with magnificent photographs. $\$ 7.25$

THE WORLD OF THE BISON by Ed Park. Towering above lesser animals in melancholy splendour and indestructible nobility s.tands the bisonthe buffalo. With words and extraordinary photographs Ed Park allows the reader to fallow the shaggy bison through their migrations in spring and fall, through summer days anc the onslaught of winter. $\$ 7.25$

\title{
SNHS ANNUAL AWARDS
}

\section{CLIFF SHAW AWARD 1969}

By decision of the Board of Directors The Cliff Shaw Award is being continued beyond the minimal 10 years of the original term. This award is given to the contributor judged by the Editor to have made the most significant contribution to the Blue Jay during the preceding year.

The 1969 award was made to John Lane of Brandon, Manitoba, by Dr. George Ledingham, Editor of the Blue Jay, for the article on hybridism in the Mountain and Eastern bluebirds that was printed in the March, 1969 Blue Jay. This article was a valuable original contribution, recording the first example of hybridism in the thrush family in North America. In addition, it was recognized that a number of other recent contributions to the Blue Jay were indirectly inspired by John Lane, the originator of the bluebird trail at Brandon, for his idea has been taken up at Indian Head by Lorne Scott, and more recently at Saskatoon by the junior naturalists of the local society there.

\section{SNHS CONSERVATION AWARD 1969}

The Conservation Award given annually by the Saskatchewan Natural History Society recognizes an outstanding contribution to conservation in Saskatchewan. This year the award was made to Lorne Scott, a young staff member of the Saskatchewan Museum of Natural History. Lorne was recognized for his conservation education activities in the Museum, for his dedicated interest in young people and their projects, and for his work on the Indian Head Bluebird Trail. In making the presentation, retiring President, Mr. W. A. Brownlee, said that natural history was both Lorne's long-time hobby and his current occupation.

The bluebird nest box project started by Lorne at Indian Head in 1963 now has 750 nest boxes. Lorne's project was inspired by John Lane and his group of junior naturalists at Brandon, and Lorne in turn is now giving encouragement to another group of juniors in Saskatoon, who hope to extend their nest box trail to meet Lorne's. 


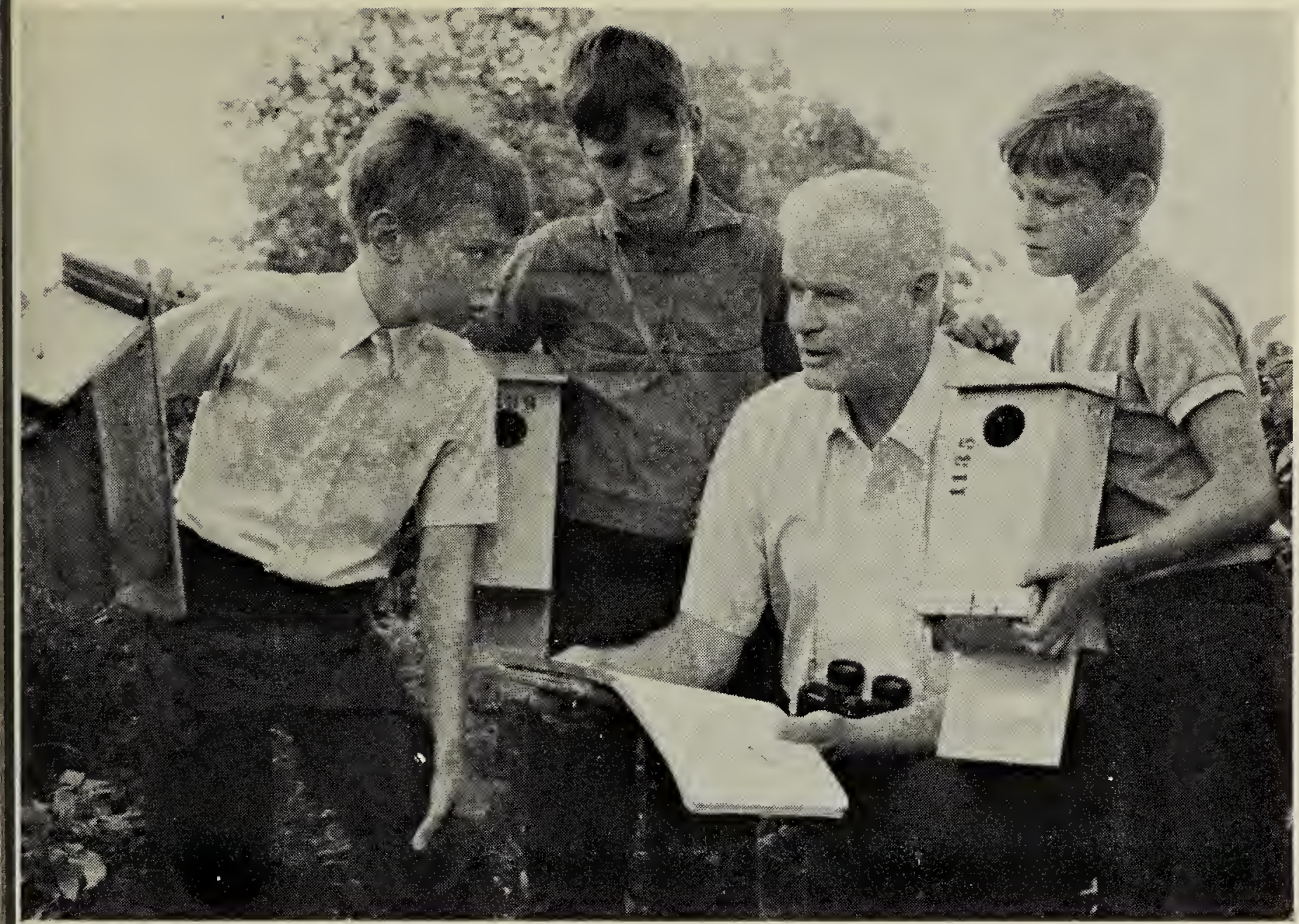

Cliff Shaw Award winner, John Lane, with members of the Brandon Junior Birders' Club.

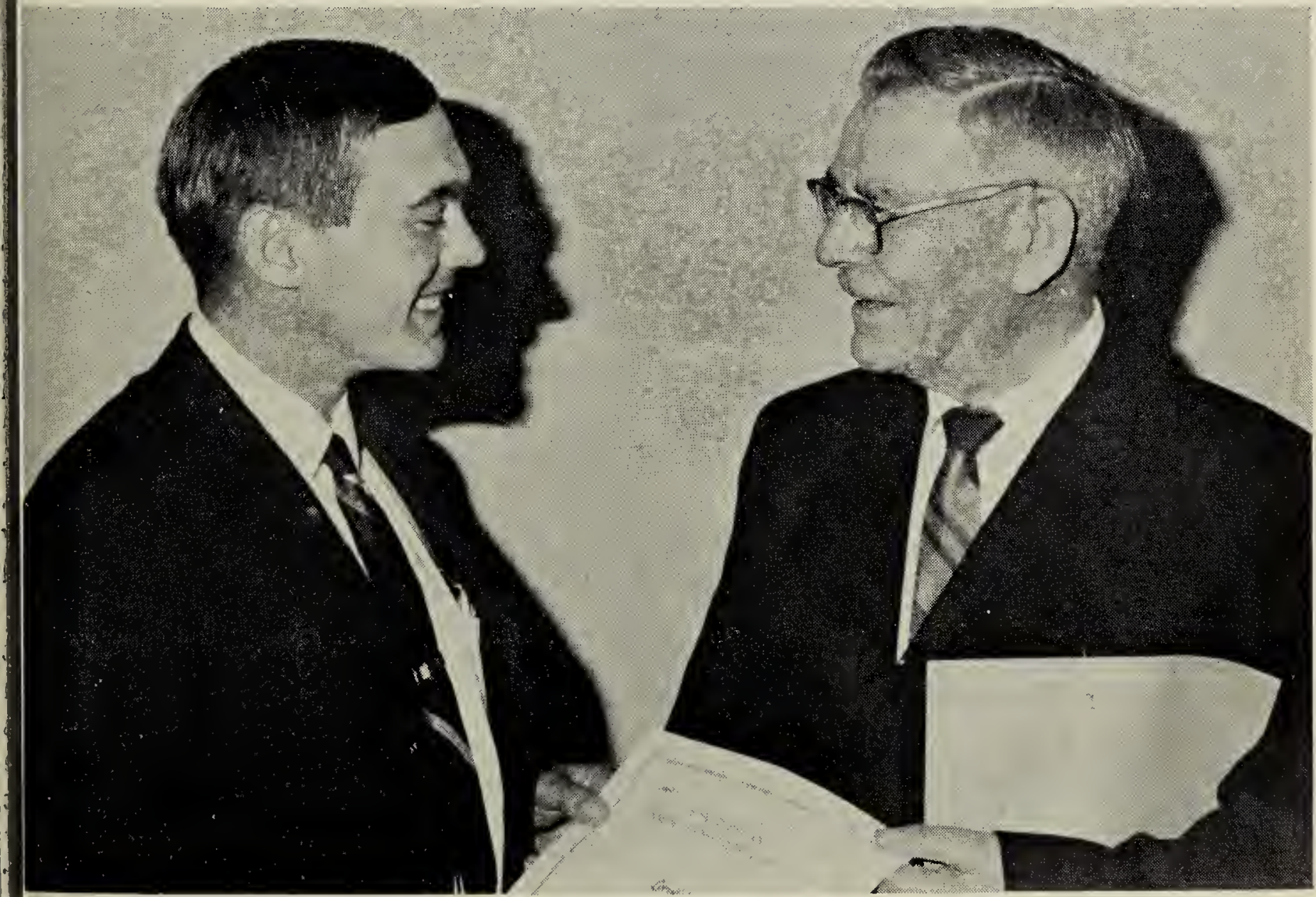

Conservation Award winner, Lorne Scott, and

Photo by Gary Seib retiring president W. A. Brownlee 